\title{
Workforce specialty review for family planning and reproductive health care 2003/2004: England, Wales, Northern Ireland and Scotland
}

\author{
Christine Horrocks
}

\section{Introduction}

This paper describes the national Family Planning and Reproductive Health Care service medical and nursing workforce for 2004, and the changes that have occurred since 1999. It addresses future workforce needs in this specialty, now known as Sexual and Reproductive Health.

Data were based on the Faculty of Family Planning and Reproductive Health Care (FFPRHC) workforce census, which has been undertaken in May annually since 1997. The 2003/2004 data were published together in 2005 as The Seventh \& Eighth Census of the Family Planning Workforce in the United Kingdom 2003 \& 2004 and are available on the FFPRHC website. ${ }^{1}$ Up-to-date information on specialist registrars was obtained from the Joint Training Committee of the Royal College of Obstetrics and Gynaecology (RCOG) and the FFPRHC, and on career grade trainees from the FFPRHC Higher Training Committee. Data on attendances at family planning clinics (FPCs) in England and Wales were provided by the Department of Health Statistics, Contraceptive Services, England, 2003-2004 and Family Planning Services, Wales, 2003-2004. Attendances for Scotland and Northern Ireland were taken from the FFPRHC 2004 census.

\section{Background}

The Family Planning Association pioneers were among the first to make contraceptive services available to women attending traditional FPCs. These became part of the National Health Service (NHS) in 1974. There are now 187 NHS contraceptive services in the UK, and 17 contraceptive services run by Brook for young people. ${ }^{1}$ Primary Care Trusts or Health Boards manage most NHS services, although some are managed by Acute Trusts.

The first consultants were appointed in the early 1990s and 73 lead clinicians were appointed or re-graded as consultants in that decade. This number has since varied, the latest census showing that 99 consultants lead services. As lead clinicians retire, consultants are often appointed in their place. The Faculty has recommended that there should be one full-time consultant in Contraception and Reproductive Health for every 125000 people. ${ }^{1}$ This is the same consultant to patient ratio as that recommended for the specialty of Genitourinary Medicine (GUM).

The UK has the highest rate of teenage pregnancy in Europe and, in 1999, the National Teenage Pregnancy Strategy for England ${ }^{2}$ was published. This aims to halve the conception rate among under-16-year-olds by 2010 . In

\section{J Fam Plann Reprod Health Care 2005; 31(4): 325-328}

\section{Faculty of Family Planning and Reproductive Health Care} Workforce Planning Committee, London, UK Christine Horrocks, MB ChB, MFFP, Chair of the FFPRHC Workforce Planning Committee and Consultant in Contraception and Sexual Health, Bristol, UK

Correspondence to: Dr Christine Horrocks. E-mail: jhct.horrocks@ukgateway.net
2000, the National Strategy for Sexual Health and HIV 3 was published to encourage more sexual health screening, including chlamydia screening, in our clinics and further integration with GUM. These measures are essential as there has been a dramatic increase of sexually transmitted infection (STI) throughout the UK. In January 2005, the Scottish Executive published its Strategy and Action Plan for Improving Sexual Health - Respect and Responsibility. ${ }^{4}$ This emphasises the convergence of family planning and genitourinary services in Scotland and the development of clinical services.

\section{Current services}

The number of women attending FPCs in England has risen gradually in the last 10 years from around 1.1 million in 1993-1994 to 1.2 million in 2003-2004. Altogether, these 1.2 million women and 106000 men attended FPCs in England about 2.7 million times in 2003-2004. The peak age for clinic attendance was 16-19 years and $40 \%$ of those in this age group seeking contraception from a medical source were clinic attenders. This compares with $25 \%$ of $20-24$-year-olds and $15 \%$ of over-25-year-olds. Most other users obtained contraception from their GP. ${ }^{5}$ In 2003-2004, 51000 women and 5000 men attended FPCs in Wales. Some $34 \%$ of women were aged less than 20 years compared with $20 \%$ in $1993-1994.6$ In same year, total attendances were about 292000 in Scotland and 61000 in Northern Ireland.

The Faculty census has shown that in 2004 nearly all services offered intrauterine device (IUD) and implant insertion. A total of 182 services provided clinics specifically for young people. In 2003, 30 services organised fully integrated contraception and GUM clinics compared with 16 services in 2001. Services have developed since the days of traditional FPCs and some centres now provide psychosexual counselling, management of the menopause, abortion, vasectomy, colposcopy, medical gynaecology, domiciliary services and outreach services to schools, prisons, drug users, the homeless, ethnic minorities and sex workers. Many services test and treat women and men for STI. Most services co-ordinate family planning training in their area.

\section{Workforce in 2004}

The accuracy of the FFPRHC census data depends on the degree of response from the services. In 2004, this response was high with 199/204 services having contributed data. The numbers of doctors working in family planning and young people's clinics have slowly declined, from 2334 doctors in 1999 to 1815 doctors in 2004. Conversely, whole-time equivalents (WTE) have increased, from 400 WTE in 1999 to 457 WTE in 2004. This indicates that doctors are working more hours in the specialty and that fewer doctors are employed on a part-time basis.

\section{Consultants}

The number of consultants in the specialty rose from 73 in 1999 to 99 in 2004, with a record number of 13 new consultant posts in the last year and 15 new consultant appointments. Seventy-seven services are now consultant 


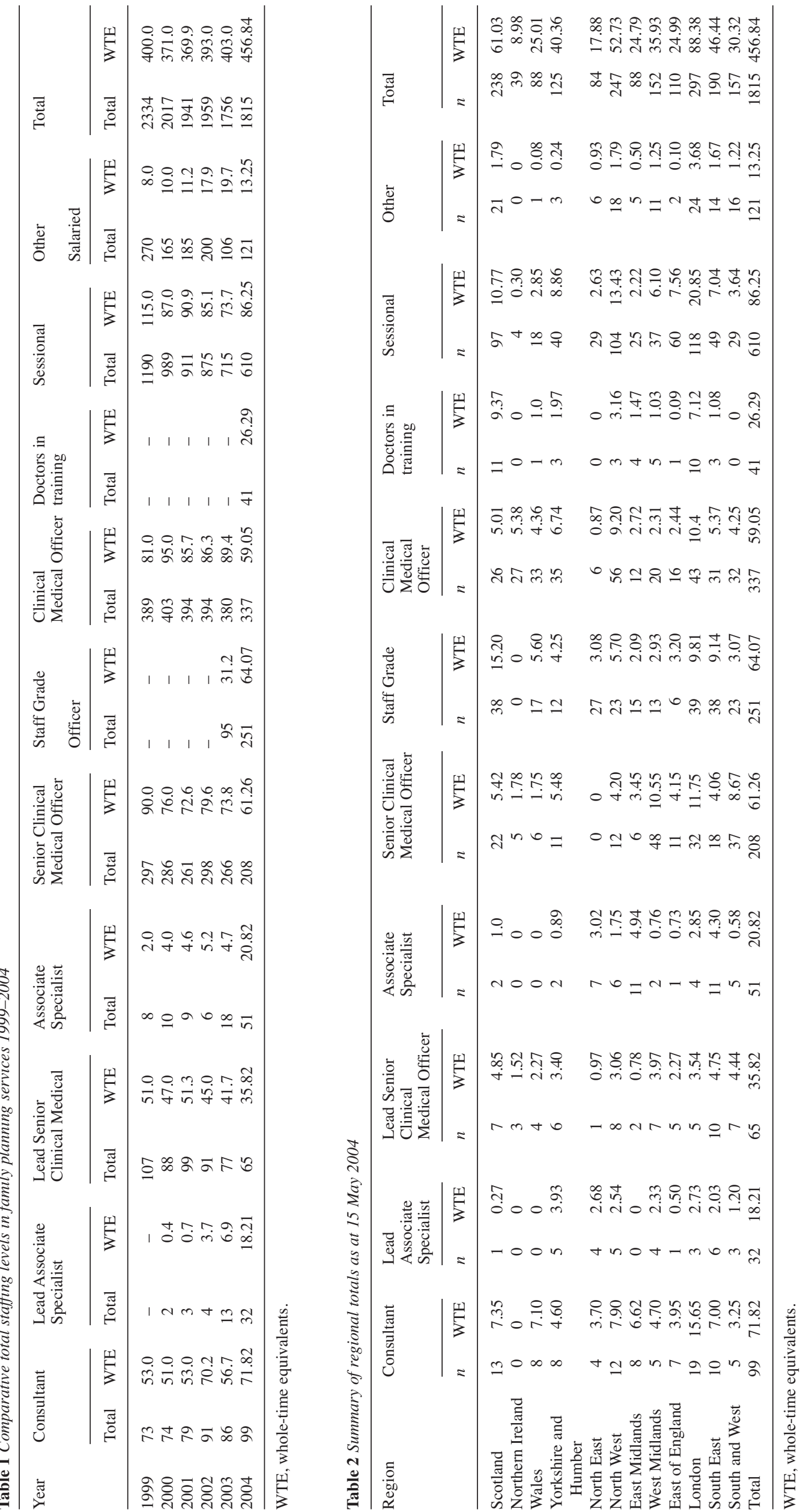


led, with 17 services having more than one consultant. There were also 12 vacancies at the consultant level at the time of the census, and Trusts plan to appoint an additional 19 consultants in the coming year. However, our census shows that there are not enough doctors in training for the specialist register to fill the posts created as consultants retire and as other Trusts decide that their service should be consultant led. Some advertised consultant posts have not been filled this year due to lack of suitable applicants. The 2004 census shows that 13 consultants plan to retire during 2004-2006, with eight planning to retire in 2005.

As mentioned previously, the FFPRHC has recommended that there should be one consultant for every 125000 people. A total of 60/99 consultants in the 2004 census worked single-handed, which is a cause for concern as regards administrative workload, clinical governance, on-call commitments and cover for leave. There are only 10 current subspecialty trainees despite 12 more vacant training places; this is due to a lack of funding and National Training Numbers (NTNs) for Sexual and Reproductive Health (see below). A working party report of the RCOG published in July 2004 on The Future Role of the Consultant states that the current situation is not sustainable; workforce calculations must take into account the required number of subspecialists and consultants with a special interest, and train them accordingly. ${ }^{7}$

\section{Other lead clinicians}

Individual services were led by Senior Clinical Medical Officers (SCMOs) until the emergence of consultants in the speciality in the early 1990s. In 2002, the transfer of terms and conditions (T\&Cs) of service of doctors in Public Health Medicine and Community Health to those of hospital doctors has meant closure of entry to the SCMO grade and possible transfer to the grade of Associate Specialist (AS). In 2004, there were a total of 97 Lead SCMOs and 32 Lead ASs. The census showed that there were 13 vacancies for Lead Clinicians in addition to consultants in 2004. There are plans to appoint five more Lead Clinicians in 2005. At present, there are 31 registered career grade trainees hoping to fill Lead AS and other senior posts. The 2004 census showed that $19 \%$ of services were most likely to be led by a Senior Nurse Manager. Consultants in different specialties, such as gynaecology or GUM, may manage some services.

\section{Senior doctors}

In 2004, because of the new T\&Cs, the number of ASs working for the service increased from 18 to 51 and the number of SCMOs decreased from 268 to 208. SCMOs have traditionally been doctors with special skills and responsibilities such as psychosexual counselling or who have acted as Faculty instructing doctors. As a result, the AS job description will include a specialist interest and administrative duties.

\section{Clinical medical officer, staff grade and sessional doctors}

The Clinical Medical Officer (CMO) grade has also been closed by the new T\&Cs, but there is the possibility for doctors who want to develop their skills to transfer to staff grade. A total of $337 \mathrm{CMOs}$ were working in this grade in 2004 and the number in staff grade increased to 251 (Table 1). Traditionally, some divisions of the service have been staffed by sessional doctors, mainly general practitioners (GPs) who want to maintain their skills in the specialty or women with family commitments wanting part-time work. The majority of junior staff in the service are sessional doctors (610 with a WTE of 86.3), many working one session or less per week. This is unsatisfactory for career progression as terms and service and employment conditions are variable and usually negotiated at Trust level. Most of these doctors do not have sickness, maternity or study leave, or security of employment. In addition, the sessional pay rate has become very unfavourable compared with GP locum pay. For these reasons, the number of sessional doctors working in the service has sharply declined since 1999 when there were 1190. There are 121 (13.3 WTE) doctors working in other grades, such as Clinical Assistant or Senior House Officer (SHO).

\section{Distribution of doctors' grades across regions}

Scotland, the North West, London and the South East are the four regions responsible for the majority of consultant appointments. Northern Ireland has no consultants in the specialty and only three Lead SCMOs. Yorkshire and Humber, West Midlands and South and West have comparatively more Lead SCMOs and Lead ASs. East Midlands, West Midlands, East of England, South and West, and South East have a higher percentage of senior doctors (SCMOs and ASs) than the other regions. Scotland, North West, East of England and London are the regions in which sessional doctors comprise the greatest percentage of the workforce (Table 2).

\section{Nurses working in the service}

The number of nurses working in family planning has increased each year from 2430 in the census 2000 to 3169 (673.4 WTE) in census 2004. A total of 158/204 services offered nurse-led clinics in 2004 compared with 127 in 2001. The number of services with nurses using Patient Group Directions has increased from 168 to 186 in 2001. In 2004, 75 services also had nurses working as independent prescribers. Most of the increase in nurse numbers is in Nurse F grade or above: from 1397 in 2000 to 2189 (482.8 WTE) in 2004. This confirms the increased responsibilities and training of nurses in microbiology and cytology testing, and in medical techniques such as implant and IUD insertion. In 2004, 17 services had nurses fitting IUDs and 41 services had nurses fitting or removing contraceptive implants.

\section{Instructing doctors}

The number of FFPRHC instructing doctors decreased from 661 in census 2000 to 566 in census 2004. Nevertheless, 1498 doctors trained for the Diploma of the Faculty of Family Planning and Reproductive Health Care (DFFP) in 2004 and 532 doctors trained for the FFPRHC Letter of Competence in IUD techniques. However, in 2004, there was no DFFP training in 48 services and no IUD training in 54 services. Where training took place, the number of trainees per service varied from 1 to 72 . Many GPs and doctors specialising in sexual and reproductive health, gynaecology and GUM request or require this training, and waiting lists are long in some areas for this and training of implant techniques due to the lack of facilities and number of instructing doctors. Services should do more to prioritise training in order to increase the skills of those in related specialties and primary care.

\section{Subspecialty training}

Before the introduction of European Community (EC) regulations in 1998, a Lead Clinician could be appointed or re-graded as a consultant. In recent years, several Lead Clinicians have accessed the Specialist Register under 
transitional arrangements of the regulations. However, the main route to become a consultant is now via obstetrics and gynaecology. Trainees compete for a NTN to enter the first 3 years of general obstetrics and gynaecology training. If they successfully complete core training (the first 3 years), they can then apply for subspecialty training in sexual and reproductive health (previously community gynaecology) to obtain a Certificate of Completion of Specialist Training (CSST) in sexual and reproductive health. This requires a further 3 years of training in an approved centre with time for research and acquisition of Membership of the Faculty of Family Planning and Reproductive Health Care (MFFP). There are 15 approved centres with 22 approved places. However, there are a number of vacant training places due to a lack of funding and NTNs rather than a lack of interest in the subspecialty. In 2003, the FFPRHC and RCOG bid for additional NTNs in England. Four ring-fenced and fully funded NTNs for sexual and reproductive health, and 63 unfunded NTNs for general obstetrics and gynaecology, were granted.

In 2001, the RCOG allowed eight post-CCST trainees in obstetrics and gynaecology to complete a 'top-up' year in sexual and reproductive health. Of these, five are now consultants in the specialty and one an AS. Five doctors who have trained with the Faculty of Public Health Medicine have taken another route: by obtaining a CCST in public health medicine and choosing to specialise in sexual health during the last years of their training. They may choose either a career in public health with special skills in sexual health, or to apply for a consultant post leading a sexual health service.

\section{Career grade trainees}

Another training route is via the Faculty's 3-year career grade training programme including acquisition of MFFP. At present this training does not lead to entry to the Specialist Register and consultant status, and is better suited to those who wish to be a senior doctor in the field. It leads to a Faculty Certificate confirming Completion of Training (FCCT). The programme started in 1999, and initially there was a transition period when experienced doctors could complete their training in less than 3 years. This is now closed to new entrants and all must undertake the 3 years, with an allowance of 6 months for previous experience. Currently there are 40 training sites and 31 registered trainees. To date, 41 doctors have completed training and have been awarded the FCCT; some have become non-consultant Lead Clinicians, others are senior doctors in their service.

\section{Other grades}

There are plans in the UK to develop a single-spine, nonconsultant career grade structure, with several tiers decided by competency. At present, doctors can only become staff grades after 3 years of experience in the field, which encourages employment of sessional doctors. This is undesirable because of the variable employment conditions. There is need for an opportunity for development of Senior House Officer posts. Services are already restructuring, with more nurse-led sessions, as nurses become capable of prescribing and taking on skills that have previously been medical.

\section{Conclusions}

The UK has the highest rate of teenage pregnancy in Europe and there are increasing rates of STI with subsequent morbidity. The family planning or sexual and reproductive health services have reacted, and expanded services as required. There is still, however, an urgent need to find funding and NTNs so that the number of subspecialty trainees can be increased to match the expansion in consultant posts. Other staff also require appropriate career structures so that they can support the service and train colleagues in primary care and related specialties.

\section{Statements on funding and competing interests \\ Funding. None identified.}

Competing interests. None identified.

References

1 Faculty of Family Planning and Reproductive Health Care of the Royal College of Obstetricians and Gynaecologists. The Seventh \& Eighth Census of the Family Planning Workforce in the United Kingdom 2003 \& 2004. http://www.ffprhc.org.uk/admin/ uploads/census0304.pdf [Accessed 16 August 2005].

2 Social Exclusion Unit. Teenage Pregnancy. London, UK: HMSO, 1999. http://www.dfes.gov.uk/teenagepregnancy/dsp_showDoc.cfm? FileName=teenpreg.pdf [Accessed 16 August 2005].

3 Department of Health. The National Strategy for Sexual Health and HIV. London, UK: HMSO, 2001. http://www.dh.gov.uk/assetRoot /04/05/89/45/04058945.pdf [Accessed 16 August 2005].

4 Scottish Executive. Respect and Responsibility: Strategy and Action Plan for Improving Sexual Health. Edinburgh, UK: Scottish Executive Publications, 2005. http://www.scotland.gov.uk/ Publications/2005/01/20603/51182 [Accessed 16 August 2005].

5 Department of Health. NHS Contraceptive Services, England: 2003-04. London, UK: HMSO, 2004. http://www.dh.gov.uk/ assetRoot/04/09/00/22/04090022.pdf [Accessed 16 August 2005].

6 Headline Statistics Wales. Family Planning Services, 2003-2004. http://www.wales.gov.uk/keypubstatisticsforwalesheadline/content/ health/2005/hdw200502031-e.htm [Accessed 16 August 2005].

7 Royal College of Obstetricians and Gynaecologists (RCOG). The Future Role of the Consultant. A Working Party Report. London, UK: RCOG Press, July 2004; 24.

\section{Book Review}

Polycystic Ovary Syndrome: A Guide to Clinical Management. AH Balen, GS Conway, R Homburg, RS Legro. London, UK: Taylor \& Francis, 2005. ISBN: 184214211 9. Price: $£ 80.00$. Pages: 210 (hardback)

Adam Balen and his colleagues have provided up-to-date, evidence-based information about this important and increasingly prevalent syndrome with its numerous consequences on reproductive and general health. With people in many parts of the Western world currently experiencing a relatively sedentary lifestyle coupled with an abundance of food, there appears to be an epidemic of obesity and consequent hyperinsulinaemia resulting in the precipitation of the clinically apparent syndrome in an increasing number of symptomless women with polycystic ovaries. This book has been published at a most appropriate time.

The authors have discussed the diagnosis of the syndrome with reference to ultrasonography and serum endocrinology, and have dealt with the epidemiology, pathophysiology and genetics of polycystic ovary syndrome to provide an insight in the current understanding of the disorder.

There are significant contributions to our understanding of hyperinsulinaemia and its shortterm and long-term health consequences. The treatment options for distressing symptoms like hirsutism and acne and also for menstrual disturbance are considered. There is an excellent chapter on the management of infertility associated with the syndrome, providing a thorough, evidence-based review of the available therapeutic options.

The format of the book is superb. Many illustrations are excellent. Each chapter is concluded with carefully worded key points, providing a concise source of revision to postgraduate students. Each chapter has a valuable list of references.

I strongly recommend this marvellous comprehensive text not only to gynaecologists and specialists in infertility but also to general practitioners who need to deal with this important endocrine disorder with its widespread manifestations. For clinicians with a special interest in reproductive endocrinology, this book is indeed invaluable.

Reviewed by R K Bhathena, FRCOG, FFFP Consultant Obstetrician and Gynaecologist, Bombay, India 